\title{
The SOUTH AFrican Journal FOR PHYSIOTHERAPY - 80 YEARS ON
}

$T^{1}$ he South African Society of Physiotherapy celebrates its 80th Anniversary this year, this provides an opportunity to consider the importance and relevance of its professional journal over the same period of time.

A professional journal contains a record of events and proceedings taking place within that professional organisation. Viewed over 80 years the physiotherapy journal demonstrates those features of the profession that endure (and those that do not) over long periods of time and over contrasting eras of social systems. The experience of the physiotherapy profession in South Africa is somewhat unique in the context of the international physiotherapy community. It encompasses a period of colonial rule, a period of severe political oppression and a subsequent period of democratic freedom. It also encompasses periods of very dramatic change in the way health care is practiced and advances made in health care technologies.

In a broad sense the physiotherapy journal describes the unique thinking, practicing and methods of solving problems by the physiotherapy profession enabling it to be a legitimate and sustainable organisation within the

EDITOR:

C.J. Eales, $\mathrm{PhD}$

University of the Witwatersrand

Assistant Editors:

- S.L. Amosun, PhD

University of Cape Town

M. Faure, Mphil

University of Stellenbosch

J. Jelsma, PhD

University of Cape Town

J. Mothabeng, Mphys

University of Pretoria

A.V. Stewart, PhD

University of the Witwatersrand

INTERNATIONAL MEMBERS:

- A. Akinpelu, $\mathrm{PhD}$

University College Hospital

Ibadan, Nigeria

- T.H.A. Kolobe, $\mathrm{PhD}$

University of Illinois, Chicago

K. Shepard, PhD

Temple University, Philadelphia

R Herbert, PhD

Sydney University, Australia

C. Partridge, $\mathrm{PhD}$

University of Kent, Canterbury health care environment. Not only does a professional journal contain scientific or descriptive articles relating to the practice of physiotherapy and health care, but advertisements, correspondence, photographs, references to policies, names and qualifications of authors, language and terminology. Viewed in this way, over 80 years, it thus presents a socio-historical record of the change and growth of the physiotherapy profession during that period.

Longitudinal studies of socio-historical changes in an organisation have to take into account the external pressures and variables impacting on the organisation, these are generally recognised to be:

i) political events or change in regime;

ii) legal or regulatory change;

iii) changes in societal norms and values; iv) change in resource availability.

Therefor, a professional journal which is a reflection of the profession should illustrate, through its contents, the way in which the organisation perceives and adapts to these external pressures. Thus a perusal over 80 years of the contents of the South African journals of physiotherapy, does indeed present to us a very changing landscape of physiotherapy practice and professional development.

For example, up to the late 1960s the majority of physiotherapists worked within bureaucratic institutionalised hospitals, all physiotherapy training, with the exception of that at Wits University, was at diploma level. The majority of articles appearing in the journal at this time relate to hospital practice and are of a descriptive and general nature. In the early 1970 s with the development of medical aid schemes, the Professional Board for physiotherapy and a university degree becoming a requisite for under graduate training, the opportunities for physiotherapists changed dramatically. Physiotherapists with new-found autonomy had to reduce any ambiguity which might have existed about their capabilities for their share holders - the public and medical profession. Articles in the journal started to reflect a more scientific enquiry and professional accountability. More articles appeared in the journal written by physiotherapists with degrees and containing greater research content using quantitative methods. The move to a university training lead to a greater number of physiotherapists taking higher degrees and publishing their original research work.

The political changes taking place in South Africa in the 1990s lead to journal articles discussing not only the very different health care policies applying to both the private and public sector but also the need for a greater understanding of broad ethical and equality principles. The global shift away from a medical model of health care, the development of professional sport involvement, recognition and acceptance of alternative health care by the public has highlighted the necessity for considerable reflection and discussion over the high degree of specialisation required in the modern physiotherapy world and the conflict between self interest and the altruistic calling to serve the public. Some of these very difficult issues which require a more self-reflective and interpretive approach are being addressed in the more recent physiotherapy journals.

The above example presenting a very brief review of articles in the physiotherapy journals provides us with a method for mapping and interpreting the development of the profession through the various eras of our life span. Using similar longitudinal approaches a considerable amount of information can be extracted from the physiotherapy journals.

And what of the future? My guess is that the journal in its current form will become a thing of the past - soon everyone will receive their "journal" electronically and digitally prepared. Gone will be printing costs and postage. In 80 years hence physiotherapists will look in amazement at dusty old paper journals residing in the depths of libraries and 1 st editions will become collectors items! Nonetheless these old journals remain part of our heritage and should be preserved with care.

The physiotherapy profession has enjoyed a very interesting 80 years, well recorded in its journals. I trust in the electronic age our history will not disappear and be forgotten by future generations but will remain in its new form for others to study.

Good luck journal, enjoy future wordy prosperity.

Pat Bow erbank, PhD 